\title{
Un niño en estado de PAisaje: AlLÁ lejOS y haCE tIEMPO DE GuILlermo EnRIQUe Hudson
}

\author{
A Boy in LaNDSCAPEHOOD: Far Away AND \\ Long Ago by William Henry Hudson \\ Adriana Kanzepolsky \\ Universidade de São Paulo \\ São Paulo, Brasil
}

\section{Resumen}

El presente artículo se interroga sobre la construcción de la memoria de infancia en Allá lejos y hace tiempo de Guillermo Enrique Hudson, concibiendo esta memoria, no tanto como una evocación de la temporalidad perdida sino de un espacio y un paisaje perdidos, el de la pampa, a mediados del siglo XIX.

Leemos aquí las estrategias de construcción de aquello que Susan Stewart denomina "la enfermedad social de la nostalgia", así como la concepción de memoria que organiza esta autobiografía de infancia.

Palabras clave: Infancia; Memorias; Pampa; Paisaje; Nostalgia; Guillermo Enrique Hudson

\section{Resumo}

$\mathrm{O}$ artigo indaga a construção da memória de infância em Allá lejos y hace tiempo de Guillermo Enrique Hudson, concebendo essa memória não como uma evocação da temporalidade, mas de um espaço e uma paisagem perdidos: o espaço dos pampas ao redor dos anos cinquenta do século dezenove.

Lemos as estratégias de construção daquilo que Susan Stewart denomina "a enfermidade social da nostalgia”, como também a concepção da memória que organiza esta autobiografia de infância.

Palavras-chave: Infância; Memórias; Pampas; paisagem; nostalgia; William Henry Hudson

\section{Abstract}

This paper explores the construction of childhood memory in Far Away and Long Ago by William Henry Hudson. We consider memory an evocation, rather than of a lost temporality, of a lost space and landscape, namely the Pampas in mid-19th Century.

We study the strategies of construction of what Susan Stewart calls "nostalgia as a social disease", as well as the concept of memory that organizes this autobiography of childhood. Keywords: Childhood; Memories; Pampas; Landscape; Nostalgia; Longings; Guillermo Enrique Hudson

Al comienzo de "El deseo de narrar", prólogo que escribe a un conjunto de relatos de Walter Benjamin, Jorge Monteleone afirma que "A lo largo de su vida Walter Benjamin supo que contar historias era un acto primigenio y 
arcaico, la rememoración de la experiencia vivida que acude al relato como la materia modelada por un artesano en la forma narrada" (MONTELEONE, 2013: 5). Y agrega que al escribir sus textos autobiográficos este narrador se distrajo en la minucia: en los juguetes, en el desembalar de las bibliotecas, en el acto de comer, o en el de consumir haschisch; como también, que al evocar su infancia -y ahí las palabras son de Benjamin- lo hizo como "una especie de conversación de un nińo con la ciudad de Berlín alrededor de 1900" (MONTELEONE, 2013:5). Todas formas de decir que la distracción en el detalle que caracteriza a estos textos, más que llevar a cabo un despliegue temporal de recuerdos se centra en una rememoración del espacio.

Aunque en principio la asociación pueda resultar extraña, contar historias concibiéndolas como la rememoración de la experiencia vivida, componer versiones de sí mismo que se detienen en lo mínimo, evocar la propia infancia, entendida fundamentalmente como un diálogo con el espacio y no con el tiempo, parecieran describir con precisión aquello que allá lejos y hace tiempo lleva a cabo Guillermo Enrique Hudson, ese "argentino que escribió en inglés".

Hablamos ahora de la rememoración de un niño en un extenso diálogo con el espacio de la pampa, de algún lugar de la pampa, en un período que va aproximadamente de mediados de la década del cuarenta a mediados de la del cincuenta del siglo XIX. Un diálogo organizado sobre los saberes del cuerpo que se hace presente en la escritura a través de los sentidos que lo muestran, pero al que en ningún momento el narrador describe. Están allí el tacto, el olfato, el oído, pero, sobre todo, la vista, en realidad, la mirada, que nunca abarca grandes extensiones y cuando lo hace es para pocas líneas más adelante detenerse en lo pequeño y el detalle; como si la mirada buscase tomar aliento para después posarse segura, descansar en el remanso de lo mínimo.

Ahora, se trata de un diálogo en el que Hudson, más que escribir unas memorias personales o familiares, escribe la memoria de ese espacio, de ese niño en situación de paisaje, pero también de algunas personas que por ahí transitaron en la época de su niñez. Es decir, lo que leemos es una memoria de la pampa a mediados de la década del cuarenta del siglo XIX, en la que evoca los diferentes estados de la naturaleza: los árboles nativos o plantados, los pájaros y quizá, por sobre todo, los cardos que reaparecen insistentemente, a veces como una maldición, porque la desmesura de su tamaño confina a las mujeres dentro de los pequeños ranchos, o porque están en el origen de los incendios de verano, y otras, como una bendición porque un año de cardos es un ańo de ganado gordo, y por el encanto que siente ante la pelusa de sus

\footnotetext{
${ }^{1}$ HUDSON, 1958.
} 
flores flotando en el aire. Pero también una memoria en la que transitan algunos de los miembros de esa sociedad dispersa en medio de la llanura: maestros que llegan y se van de la casa de los Hudson, vecinos ingleses y criollos, vagabundos y mendigos, más o menos excéntricos.

Como dijimos, Monteleone señala que para Benjamin contar historias era "un acto primigenio y arcaico"; por su parte, Arturo Carrera quien, en el bello "1948: Hudson, un recuerdo feliz" se centra en el narrador y no en el acto de narrar, escribe que Hudson era "un laberíntico narrador de fábulas", y que en la lectura de sus textos encuentra "una voz: la del abuelo que al narrar y al leer mágicamente murmura y al mismo tiempo canta [...]” (CARRERA, 2009).

Un narrador de fábulas, es cierto, en un texto en el que los animales y los elementos de la naturaleza son protagonistas, y en el que también, y en sus momentos menos felices, escuchamos la voz de un adulto desilusionado y escéptico frente al paso ineludible del tiempo y al advenimiento del progreso. ${ }^{2}$ Pero pienso que lo que se escucha, sobre todo, cuando Hudson evoca su niñez es la voz y la perspectiva del narrador de un cuento de hadas que construye el espacio de la infancia -el afuera pero también el espacio interior- como un universo encantado, como un universo que se revisita en el momento exacto que precede al despertar del sueño. Un tiempo detenido, encapsulado en ese paisaje al que se quiere protegido de la historia.

Como si cuando al final de su vida Hudson vuelve a través de la escritura al mundo de su niñez lograra por fin cumplir con un deseo imposible que confiesa haber sentido en el momento en que su adolescencia se aproxima y con él el fin de sus años felices. En "Fin de la infancia", el capítulo XXIII, en el que comienza a hacer el duelo por el pasaje a la adolescencia, y uno de los tres en los que la perspectiva infantil desaparece y se lee la voz del adulto que hace el balance de lo perdido, se pregunta: “¿Qué deseaba yo entonces? ¿Qué quería yo tener? Si hubiera sido capaz de expresar lo que sentía, habría replicado: quiero conservar lo que poseo" (HUDSON, 1958: 328). Conservar lo que en la página siguiente define como "la alegre emoción que convirtiera [su] mundo en un reino encantado" (HUDSON, 1958: 329).

El reino encantado, dice la cita, es una disposición alegre del ánimo y tal vez convenga pensar que aquello que la escritura recupera no es la infancia como algo que se le presenta por entero y sin fisuras, como una visión que le llega de manera involuntaria e incluso invasiva, tal como asegura detalladamente en el primer capítulo, sino que aquello que recupera muchas veces en el transcurso del texto es la disposición de la mirada del niño. Y es esa dispo-

\footnotetext{
${ }^{2}$ Me refiero al tan remanido ejemplo de los inmigrantes, italianos fundamentalmente, cazadores de pájaros frente a los argentinos de su época que no los cazaban, o a la conversión de esa suerte de huerto cerrado en el que habitó a campos descaracterizados por la agricultura.
} 
sición la que nos lleva a hablar del narrador de un cuento de hadas; la disposición de la mirada pero también el eco de la voz de un narrador de este tipo de cuentos, junto a la reminiscencia de algunos relatos que forman parte de nuestra propia memoria de infancia.

Esa disposición del ánimo y de la mirada sirve de emplazamiento para contar el espacio de la casa, un extraño mundo rodeado por árboles encantadores pero también por un foso, y habitado por un montón de ratas y ratones de diferentes tamaños para los cuales los restos de la faena del ganado constituyen una mesa servida con la que se banquetean, convirtiéndose así en un espectáculo fascinante para los nińos, quienes se sientan quietos a observarlos; una escena que relata de forma invertida el encantamiento de las ratas en el en "El flautista de Hamelin".

Por otra parte, es esa disposición también la que organiza, en menos de una página, el relato de la historia política de la Argentina, desde la llegada de los primeros pobladores, procedentes "de pueblos en que la gente acostumbraba sentarse a la sombra de los árboles, o suponían necesarios el grano, el aceite y el vino" (HUDSON, 1958: 86), unos hábitos que olvidan con el paso de dos o tres generaciones hasta convertirse exclusivamente en criadores de ganado y cazadores. Gentes que, luego de la independencia del país, se envuelven en guerras civiles a pico de cuchillo y terminan sumiéndose "cada vez más hondamente, en una vida ruda y salvaje” (HUDSON, 1958: 87).

Articulado sobre la relación de esa gente con los árboles, en la que traza un arco entre el recuerdo de los hábitos europeos y el olvido en que caen los árboles en la pampa, los que al momento de su niñez sólo subsisten como "restos de un pasado desaparecido", el fragmento construye un relato del pasaje de la civilización a la barbarie, en el que reencontramos algunas líneas maestras del Facundo de Sarmiento. ${ }^{3}$ En particular, aquella que concibe a la pampa como una sinécdoque de la Argentina, ${ }^{4}$ y la conversión de sus pobladores de agricultores en bárbaros cazadores. Pero se trata de líneas o núcleos a los que se aproxima en clave de leyenda, en donde el tiempo de la política que articula el Facundo y lo tensa entre el pasado y el futuro se trueca por el tiempo del cuento de hadas, un tiempo lejano e irrecuperable pero también intocado. ${ }^{5}$

\footnotetext{
${ }^{3}$ Recuérdese que hay una coincidencia de temporalidades entre la pampa de su niñez que Hudson evoca a comienzos del siglo XX y la pampa que Sarmiento "describe" en su libro de 1845.

${ }^{4} \mathrm{Al}$ respecto, Oscar Terán, en "Lección 3. La Generación del 37: Sarmiento y Alberdi”, escribe: “[...] luego de describir la selva y los Andes, Sarmiento se detiene en la pampa y decide prácticamente que la Argentina es la pampa.” Y enseguida se pregunta: “QQué es la pampa que Sarmiento (que nunca ha visto la pampa) describe? Es una llanura infinita donde la mirada se pierde" (TERÁN, 2008: 77).

${ }^{5}$ En este sentido es interesante recuperar una reflexión de Tulio Halpein Donghi en el "Prólogo" a Campaña en el Ejército Grande aliado de Sud América, donde señala que para Sarmiento, San Juan, en oposición a las ciudades del litoral rioplatense que, "gracias al comercio europeo [...] [goza-
} 
Son aún esa perspectiva y esa temporalidad las que presiden la evocación de la primera persona que recuerda ajena al círculo doméstico: un inglés, al que llamaban capitán Scott, quien de tanto en tanto aparecía por la casa con los bolsillos cargados de golosinas. Además de gustarle los niños, "solía venir de un lugar lejano y maravilloso, donde se hacían las ciruelas azucaradas" - dice el narrador en el capítulo I (HUDSON, 1958: 29) (cursivas mías).

La casa, la historia del país, los visitantes, todos evocados desde la perspectiva de su pertenencia a un lugar lejano y maravilloso, en el cual la vida del niño se va desarrollando; todos recordados en su condición de moradores de aquello que Martínez Estrada definió con precisión como el espacio de la querencia, un espacio al que, como se ha repetido hasta la saciedad, Hudson añora pero nunca regresa. ${ }^{6}$

"A cada cosa que miró y nombró le formó una imagen en forma de relicario", afirma Arnaldo Calveyra hacia el final de Allá en lo verde Hudson, para proponer enseguida que estas memorias son un libro fundador de la literatura argentina (CALVEYRA, 2012: 154). No me voy a entrar en este momento en el debate acerca de la problemática pertenencia de Allá lejos y hace tiempo a la literatura argentina, un debate que como se sabe atraviesa gran parte de las lecturas sobre este texto, ${ }^{7}$ sino que me interesa tomar la imagen de Calveyra para pensar que cada capítulo adquiere la forma de un relicario, de un pequeńo relato independiente e intenso que se conecta con los demás por un hilo tenue y acumulativo, en el que cada imagen, cada estampa de la infancia vale por sí misma, puede leerse como un relato cerrado pero también como un eslabón del conjunto. Un relicario, por otro lado, porque cada estampa está labrada simultáneamente con la precisión de la miniatura, con su concentración, pero también con una suerte de fuerza contraria y casi

ban] de una prosperidad creciente", "[...] era centro de un vasto oasis en que España había reconstruido en lenta labor los rasgos de una cultura mediterránea; un oasis de vides y olivos, una ciudad de artesanos, muleteros y viñadores [...]" (HALPERIN DONGHI, 1988: VII).

A partir del comentario de Halperin Donghi, podemos ver que en ambos casos hay una lectura política del presente en clave de leyenda, donde San Juan, el espacio natal de Sarmiento, conserva aún aquello que la pampa de Hudson perdió. No se trata, en este caso, del tiempo del Facundo sino del de Recuerdo de provincia, la autobiografía de Sarmiento.

\footnotetext{
${ }^{6}$ Escribe Martínez Estrada: "El sentimiento de la nacionalidad en Hudson, tan hondo, estaba ligado exclusivamente a sus recuerdos: casa, familia, campo, animales, flores, vecinos, costumbres, rasgos personales y característicos; pero de ninguna manera a la historia, a la política, a ningún dato de los que configuran a la nación. Su añoranza del país en que había nacido y vivido treinta y tres años era, limpiamente, el de la 'querencia'” (MARTÍNEZ ESTRADA, 2001:157).

${ }^{7}$ Con un grado mayor o menor intensidad y detalle la pregunta por esta pertenencia está presente, entre otros, en el libro de Martínez Estrada que acabamos de mencionar, pero también en textos más recientes, como "Entre el deseo y la memoria: relatos de viaje en el Río de La Plata, de Silvia Rosman (ROSMAN, 2005: 131-140) o en "El exiliado nato", el prólogo de Jean Franco a la edición de Ayacucho de Allá lejos... (FRANCO, s/f: IX-XV)
} 
imperceptible que trabaja por su disolución, por el desvanecimiento de sus imágenes que se diluyen del mismo modo que los seres que aparecen y desaparecen de la vida de este niño, sin demasiadas explicaciones, tragados a veces por la pampa, tragados otras, por la historia política de Argentina, llevados por las precarias condiciones de salubridad. Desapariciones que hacen que más de una vez los capítulos consignen la pena por no haber vuelto nunca más a saber de esos sujetos, que en algún momento y por algún motivo, su excepcionalidad en el trato con los niños, su sorprendente belleza, la dádiva de un regalo inesperado, el tono de una risa o una voz, los recortaron nítidos y singulares en su memoria.

\section{¿Por dónde empezar?}

La levedad de la lengua, ese afinamiento del lenguaje al decir de Italo Calvino, ${ }^{8}$ el registro de las sensaciones, el recorte de los episodios, el arrobamiento frente a la naturaleza, la oposición ciudad campo y la opción por el segundo, la conversión de los recuerdos en materia de la narración, el contar "como un acto primigenio y arcaico", el dejar fluir el relato como si se tratase de una narración oral son todos procedimientos que podemos reconocer en el transcurso de la lectura de Allá lejos y hace tiempo. Procedimientos u operaciones concretas para sortear aquello que con claridad Virginia Woolf describió como las dificultades a las que se enfrentaba para escribir sus memorias. La cito: "En primer lugar, -escribe- el enorme número de cosas que recuerdo, y en segundo lugar el número de distintas maneras en que cabe escribir unas memorias" (WOOLF, 1982: 93).

Esa pregunta que de modo explícito leemos a comienzos de "Apunte del pasado" de la escritora inglesa y que se desdobla en la página siguiente en una serie de posibilidades para abordar el mismo recuerdo o la misma imagen, está presente, aunque se la omita o soslaye, en la mayor parte de las autobiografías o memorias de infancia. No sólo porque, como señala Agamben, el hombre para constituirse en sujeto del lenguaje necesita despojarse de la infancia ${ }^{9}$ sino también, y en un sentido complementario, por la distancia infranqueable que se abre entre el sujeto que rememora y ese otro que es el

\footnotetext{
${ }^{8}$ Escribe Calvino: "La levedad para mí se asocia con la precisión y la determinación, no con la vaguedad y el abandonarse al azar" Y, entre las acepciones de esta palabra, unas líneas más abajo anota: "Un aligeramiento del lenguaje mediante el cual los significados son canalizados por un tejido verbal como sin peso, hasta adquirir la misma consistencia enrarecida" (CALVINO, 1989: 28).

${ }^{9}$ Transcribo el fragmento que parafraseé en el cuerpo del texto: "El hecho de que el hombre tenga una infancia (que para hablar necesite despojarse de la infancia para constituirse como sujeto en el lenguaje) rompe el 'mundo cerrado' del signo y transforma la pura lengua en discurso humano, lo semiótico en semántico" (AGAMBEN, 2003: 79).
} 
niño evocado. Una distancia, que al reflexionar sobre la escritura de sus propias memorias de infancia, le hace decir a Tununa Mercado: "Todo el tiempo sé que esa nińa que yo era deja de serlo cuando la narro, que en esa búsqueda seguiré perdiéndola [...] (MERCADO, 2009: 31-36).

Pero creo que hay algo más; la primera escena o la primera imagen, porque muchas veces las memorias comienzan por una imagen borrosa o no, entrecortada y dichosa - para parafrasear a Norah Lange- (LANGE, 1957: 9), o no, se quieren o resultan una condensación de las líneas maestras que articulan esas memorias, aquello que Julio Premat, al hablar de los comienzos de las autobiografías de infancia, califica como "una última palabra, o un testamento" (PREMAT, 2014).

Es así que, y para citar sólo algunos ejemplos de la literatura argentina, Victoria Ocampo (OCAMPO, 1982), como tantas veces se ha señalado se entretiene durante varios capítulos hablando de su linaje para no hacer hablar a la niña; y es el enraizamiento en y el conflicto con ese linaje los que determinan la dirección de sus memorias y de su vida. O, por el contrario, las memorias de Norah Lange, que tienen un comienzo excéntrico, porque empiezan por el desplazamiento y el desarraigo, como observa Sylvia Molloy (MOLLOY, 2005), pero también con un recuerdo que es una imagen entrecortada, dichosa y empańada, y son ese entrecortamiento y esos desplazamientos los que dictan el tono de la narrativa fragmentaria sobre la que se organiza su relato.

Si para decirlo rápidamente, Victoria Ocampo se concentra en el linaje y Lange en el desplazamiento, Tununa Mercado, en La mdriguera de la década del noventa, inicia sus memorias de infancia con la descripción de la casa materna a la que evoca como un continuum del cuerpo de la nińa que fue, y en adelante será la relación entre el adentro de la casa y el afuera de la ciudad, lo que organice la evocación de su niñez.

O, para abundar algo más, pensemos en Sarmiento, quien en una suerte de prólogo se dirige a sus compatriotas, como no podía ser de otra manera, pero el cual en el capítulo siguiente, el primero, comienza por hablar de los árboles, las palmas, para llegar al espacio de su casa.

También Hudson habla de los árboles en el capítulo inicial de Allá lejosy hace tiempo y nuevamente en este punto encontramos la diferencia de perspectiva que observábamos en relación al relato del devenir histórico de la pampa y sus pobladores. Mientras en Recuerdos de provincia, (SARMIENTO, 1970) Sarmiento "politiza" la existencia de estos árboles, para construirles un linaje, en el que cuenta su trayecto desde Chile hasta San Juan, Hudson se detiene en el valor de ese arbusto pampeano como mojón para los viajeros en medio del espacio inmenso de la pampa pero, sobre todo, se demora en ellos para 
consignar que esos árboles eran para los niños de la familia Hudson "la más espléndida casa de juegos" (HUDSON, 1958: 23). Una declaración dicha al pasar que pone en escena, una vez más, la recuperación de la dichosa perspectiva infantil que articula el recuerdo.

En esta breve serie, Sarmiento, Victoria Ocampo y Hudson demoran el comienzo, ponen en escena la dificultad que presupone siempre la pregunta acerca de por dónde comenzar. Inclusive, la pregunta acerca de cuál es el comienzo de la infancia, cuál es el principio de la narrativa.

En el caso específico de Hudson: ¿cómo echar a andar un relato que se propone recuperar esa disposición feliz del ánimo, como ya mencionamos tantas veces? $\mathrm{O}$ ¿Por qué y para qué volver a la infancia pocos años antes de la muerte y en el medio de una enfermedad que lo tiene en cama durante semanas? Una actividad que de algún modo cierra un ciclo que se inicia al comienzo de la adolescencia, cuando otra enfermedad, la primera que lo postra, lo aparta de las actividades al aire libre que lo hacían feliz y lo conduce a la lectura como un sustituto poco apreciado ${ }^{10}$ Es decir, ¿cómo entrar a la memoria, para qué y qué narrar? Y tal vez la pregunta más importante es: ¿cuál infancia contar? ¿Qué infancia construir en el relato?

Hacia el final de $E$ a história começa Amós Oz sostiene que los contratos de lectura iniciales proponen, a veces, un juego de ajedrez o de póquer, otras, un galanteo burlón, que promete lo que no da, o que entrega sólo una promesa; pero que en ocasiones son una invitación a bailar (OZ, 2007: 131). Si pensamos en las tres primeras páginas de Allá lejos y hace tiempo, las que claramente establecen un contrato de lectura y reflexionan acerca de la poética de la memoria, sus alcances y límites, algo sobre lo que Hudson volverá en reiteradas ocasiones a lo largo del texto, en las que señala la dificultad que presupone la escritura autobiográfica, lo que recibimos es una invitación, un

\footnotetext{
10 "Escena textual primitiva" llamó Sylvia Molloy a la frecuente representación del acto de lectura en las autobiografías hispanoamericanas, a punto tal de considerarla como un autobiografema básico, en el mismo nivel que "el primer recuerdo, la elaboración de la novela familiar, la fabulación de un linaje".

La escritora considera que "el encuentro del yo con el libro es crucial" y que con frecuencia este encuentro se dramatiza en la escritura como un momento que le confiere sentido a la vida entera (MOLLOY, 1996: 28).

En el caso de Hudson la relación con esta escena es ambigua; la misma se hace presente pero su importancia se niega o se retacea; es el infortunio de la enfermedad lo que lo lleva a la lectura, en detrimento de lo que realmente le producía placer. A lo largo de todas sus memorias de infancia, el aprendizaje formal aparece connotado como un obstáculo que le restaba tiempo a lo verdaderamente importante.

Más allá del aspecto de impostura que pueda tener esa posición, ya que quien la enuncia es un escritor, pienso que en su caso específico puede concebírsela como un elemento más en la construcción de la perspectiva infantil que organiza la narración de Allá lejos y hace tiempo.
} 
convite a la mirada, a volver a mirar con él aquello que se le presentó involuntariamente y de una vez y para siempre como un don.

Escribe Hudson que a algunos hombres, "en ciertas vidas y en un momento psicológico especial", el pasado "se le[s] revela bruscamente, como un milagro" del que nada ha sido borrado (HUDSON, 1958: 20).

Es decir, la memoria es involuntaria, y que se entregue completa es una dádiva que la vida les concede a algunos pocos individuos, entre los que obviamente se cuenta.

En esta escena primera, la memoria se presenta como un don, como un regalo que le hace el tiempo, que lo sorprende en medio de una enfermedad, lo asombra, lo detiene en su encantamiento, y vuelve a asaltarlo durante algunos años. Se trata de una suerte de trance o de visión, a la que al día siguiente tratará de salvar del olvido y que, pasados tres años, durante los cuales la visión lo asalta y lo lleva a la escritura, lo obligará a efectuar operaciones de recorte, a dejar de lado material por el tamaño desmesurado que había alcanzado el libro.

En apariencia nada más lejos de esa angustia confesada por Tununa Mercado y compartida por otros escritores contemporáneos acerca de la relación que se establece entre la escritura de la memoria y la pérdida del pasado, entendida la primera como aquello que delimita justamente lo irrecuperable, ${ }^{11}$ nada más lejos que la duda frente a la fidelidad de los recuerdos.

Habría que preguntarse, entonces, el por qué de esa insistencia de Hudson a la largo del libro en consignar la dificultad que enfrenta ante las memorias de otros escritores, cuando intenta encontrar una imagen fiel del pasado y la absoluta fe que le concede a su propia memoria en la escena inicial. ${ }^{12}$ Pienso que esa oposición entre el lector de memorias, que razona y

\footnotetext{
${ }^{11}$ Cf., entre otros, "Lengua simple: nombre" de Sergio Chejfec, quien claramente afirma: "La lengua se confunde con el pasado, pero escribir no es recordar; sino al contrario, delimitar lo que es imposible de recuperar" (CHEJFEC, 2005: 205).

${ }^{12}$ Hay un juego que se reitera en algunos pasajes de Allá lejos... en los que Hudson señala la dificultad que suelen tener los memorialistas de ser fieles a los episodios y sentimientos del infante, para detenerse inmediatamente en un ejemplo que excepcionalmente prueba lo contrario. La recurrencia de estos episodios pone en evidencia claramente que, a medida que avanza en la escritura del libro y se ve obligado a elegir recuerdos, a reorganizarlos, a trabajar la escritura de la memoria para alejarse de esa imagen primitiva, se le presenta un problema ético en relación a la verdad. Estos fragmentos simultáneamente muestran el problema y lo retacean, lo esconden o disimulan. Es así que escribe: "Otra dificultad, para los que escriben respecto de su infancia, estriba en que el inconsciente artístico penetra clandestinamente o se infiltra, para borrar líneas impropias y manchas o para retocar, colorear, sombrear y falsear el cuadro. El pobre autobiógrafo, naturalmente, desea hacer su personalidad tan interesante para el lector como le parece a él mismo. Yo siento esto con vehemencia leyendo las reminiscencias de los primeros años de otros hombres" (HUDSON, 1958: 259) E inmediatamente agrega: "Hay, empero, algunas notables excepciones. Juzgo como la mejor que conozco La historia de mi infancia, escrita por Sergio Akasakoff. En ella, el relato no fue falsificado, simplemente porque el carácter, gusto y pasiones de su temprana adolescencia, el intenso
} 
analiza, marcando siempre la incompletud y la falta, y el narrador de memorias, que no duda, que no sospecha ante su propio relato se vincula justamente con el modo cómo la memoria llega, con el modo cómo irrumpe, con eso que describíamos como un don, un don que le que le da precisamente el tiempo, que le regala el tiempo. ${ }^{13} \mathrm{El}$ tiempo de la nińez que la memoria le entrega a Hudson de una vez y para siempre, como un tiempo definitivo, intocado, porque, como señala Martínez Estrada, Guillermo Enrique Hudson nunca sale completamente de la infancia. ${ }^{14}$ Quiero decir que esas imágenes le dan el tiempo perdido, el tiempo dejado en otro espacio y en otra lengua, en relación al cual, aunque parezca contradecir lo que afirmamos más arriba, la escritura constituye un acto más en ese camino de no retorno. Recibir la infancia toda entera y fijarla en la escritura, traducirla a otra lengua, la lengua de la madre, pero no la lengua del país en que nació, es un gesto que se suma a esa serie de gestos que lleva a cabo desde que sale de Argentina. Esto es, volver a ese espacio de infancia a través de la escritura para dejarla intacta en el recuerdo, como una transparencia sin las veladuras ni las modificaciones inherentes a los procesos de la memoria y del olvido.

Desde ese primer comienzo el libro instaura dos voces, que en adelante el relato despliega en una especie de contrapunto: la voz asombrada, la perspectiva encantada que aquí se instaura desde el momento en que tiene la visión del pasado y que le confiere una suerte de excepcionalidad, como excepcional se construye a lo largo del texto en su capacidad de gozar de la naturaleza; ${ }^{15}$ y una segunda voz, la del adulto, que reflexiona acerca de las infidelidades de la memoria, una voz, que también situada en el presente, -el

amor por su madre, por la naturaleza, por todo lo silvestre y por el deporte, continuaron en él sin variar hasta el fin, conservándole con un corazón de niño, capaz, después de largos años, de revivir mentalmente lo pasado, de pintarlo con sus verdaderos frescos y originales colores" (HUDSON, 1958: 259). Pienso que la extensa cita habla por sí misma y vuelve innecesarias las comparaciones con el propio Hudson y su texto.

${ }^{13}$ Como resulta evidente esta afirmación remite a las reflexiones de Jacques Derrida en Dar (el) tiempo. La moneda falsa.

El vínculo entre tiempo y don es uno de los ejes que articulan el libro de Derrida. Cito un breve fragmento de "El tiempo rey", en el que el filósofo afirma: “'Dar (el) tiempo', [...] quiere decir normalmente dar algo distinto del tiempo pero algo distinto que se mide con el tiempo como elemento suyo" (DERRIDA, 1995: 36). Pienso que lo instigador en el caso de Hudson, en el marco de esa escena que podemos calificar como epifánica, es que la felicidad que produce la visión es la del tiempo recuperado.

${ }^{14}$ Lo cito: "[...] Hudson no ha dejado tras sí su infancia, sino que la ha conducido cuidadosamente a lo largo de su vida" (MARTÍNEZ ESTRADA, 2001:49).

${ }^{15} \mathrm{Al}$ respecto, en "Fin de la infancia" anota: "Volviendo a mi propio caso, no sabía ni podía saber, que era excepcional. Mi amor por la naturaleza consistía en algo más que el sentido de placer por el sol, por la lluvia, por el viento, por la tierra y por el agua y por la libertad de movimiento que es universal entre las criaturas, pero que se debía, en parte, a una facultad que no es universal ni es común” (HUDSON, 1958: 330). 
futuro del tiempo que recupera- advierte sobre el fin del mundo que narra. No el fin de sus experiencias personales sino el fin del espacio de la pampa tal como la conoció.

He aquí, entonces, el primer tiempo del relato y el primer comienzo, el tiempo de la vejez en el que el pasado vuelve completo y sin fisuras. Y en ese punto la narración parece echarse a andar con un tropo clásico, la descripción de la casa paterna. Leemos: "La casa en que yo nací en las pampas sudamericanas, era muy apropiadamente llamada 'Los veinticinco ombúes', porque había allí justamente veinticinco de estos árboles indígenas de gigantesco tamaño" (HUDSON, 1958: 22).

Sin embargo, nada sabremos de la casa hasta el final del capítulo, que se interna en la descripción de los árboles, los ombúes pero también en la de otro árbol, único en su especie, al que llamaban "El Árbol", y en el que hace una breve presentación de la pampa, a la que compara con una mesa de billar pero todavía no con el mar, como lo hará en el capítulo siguiente, cuando recuperando un tópico de época, común a los relatos de viaje, escribe que el campo es "chato como el mar".

Acerca de la familia tampoco nos informa nada, a excepción de la descripción de lo que denomina el cuadro de la madre leyendo al caer la tarde. Un pasaje que puede interpretarse como un desplazamiento de la clásica escena del autobiógrafo con el libro en la mano, como ya hemos comentado en la nota $11 .{ }^{16}$

$\mathrm{Si}$, como dijimos, a lo largo de sus memorias de infancia, ni la lectura, ni el aprendizaje formal son actividades valorizadas o recordadas con placer, porque lo privaban del contacto con la naturaleza y el aire libre; por el contrario, la madre, el afecto más importante en su vida, es recordada no sólo como una mujer sumamente laboriosa y creativa en lo concerniente a las tareas domésticas sino como una distinguida lectora. Una imagen que, por cierto, es disruptiva en la serie de mujeres representadas como madres en los textos del XIX hispanoamericano, dentro de la cual es paradigmática la evocación de Paula Albarracín ante el telar doméstico. Pienso que cabe entender esa insistencia en la evocación de una madre lectora como uno de los modos que encuentra Hudson de dejar claro que su gusto por la naturaleza fue una opción en un hogar en el que se valoraba la vida intelectual.

\footnotetext{
${ }^{16}$ Cito el pequeño fragmento: "También se me presenta el cuadro de mi madre, al caer la tarde, cuando los chicos, después de nuestra merienda de pan y leche, nos juntábamos en nuestra última y alegre jugarreta sobre el pasto, delante de la casa. La veo sentada afuera, observando nuestras diversiones, con la sonrisa en la mano, el libro descansando sobre la falda y los últimos rayos del sol poniente iluminándole el rostro" (HUDSON, 1958: 28).
} 
La imagen rápida de la madre lectora, entonces, a quien sitúa en el borde entre la casa y el campo, para después detenerse algo más en la relación con "Pichicho", el perro de la familia, llamado así, con ese nombre genérico con que se llama a los perros en castellano.

Por último, el relato se demora con cierto detalle en la descripción de dos personajes ajenos al ámbito familiar, el capitán Scott, al que ya nos referimos más arriba y un ermitaño, que cada tanto caía por la casa y los asombraba por su indumentaria y su lenguaje.

Seguimos en la prehistoria del relato, en algo que la visión parece no haberle devuelto. A tal punto que escribe: "Todos estos recuerdos de mi niñez, encuéntranse comprendidos entre los tres, cuatro y cinco ańos de edad, período que, para los ojos de la memoria, aparece como ancho plano borrado por una baja niebla" (HUDSON, 1958: 27). Un momento en que el texto deja claro que la memoria no le pertenece, que la infancia todavía no habla y no le habla. Una época sobre la cual escribe que únicamente podría "contar los rumores" de lo que fue o hizo ese otro, ajeno, al que recuerda solamente como un "animalito salvaje corriendo sobre sus patas traseras", pero ya curioso, "interesado en el mundo en que se encontraba" (HUDSON, 1958: 37).

El verdadero comienzo del relato se da recién en el capítulo siguiente, a una edad precisa, sus cinco años, y en un día particular, el del viaje hacia la nueva casa en el transcurso del cual descubre la pampa, la ve por primera vez. Es decir, no hay memoria y no hay infancia en la que se reconozca antes de ese viaje. Es ese trayecto y lo que recuerda o fabula que vio en su transcurso los que le permiten trazar una continuidad entre el niño que fue y el adulto que recuerda y construye la nostalgia. Un niño que, en adelante, puede entrar en detalles sobre lo que vio y no sólo recuperar el rumor acerca de lo que le dijeron de sí.

Al contrario de la imagen entrecortada, dichosa y empañada que abre Cuadernos de infancia de Norah Lange, la imagen que construye Hudson es un cuadro sin fallas de la planicie en un día de invierno. Están allí los resplandores del agua, los pastos verdes pero sin flores, los rodeos de ganado, algún jinete ocasional, algunos montes como una suerte de mojones que marcan la existencia de una estancia, el mugido de las vacas y el balar de las ovejas, que terminan por adormecerlo. Esa imagen absolutamente plácida y continua como la memoria que se le entrega, se interrumpe abrupta con una sensación en la que el niño aparece claramente por primera vez duro de frío, sin poder tenerse en pie por el sueño y retirado del coche por los brazos de alguien que imaginamos atrás del impersonal "me bajaron". El viaje termina con el siguiente comentario: "Sólo volví a recobrar mis sentidos cuando ya 
obscurecía y me bajaron del coche tan duro de frío y amodorrado que apenas podía estar en pie" (HUDSON, 1958: 38).

Diría que es en ese punto donde el relato comienza. En esa imagen que contrasta la plácida transparencia del paisaje, al que imaginamos un compendio de todas las veces que lo vio en el transcurso de su vida desde la altura de un caballo o de un coche a caballo, y la sensación de frío y entumecimiento, en la cual parece que quien habla es el niño, alguien que es pura sensación.

"A la mañana siguiente me encontré en un nuevo y extraño mundo", escribe Hudson a renglón seguido (HUDSON, 1958: 39). Es esta la frase que inaugura el relato de la nostalgia por ese espacio perdido, por ese lugar evocado y reconstruido como un espacio feliz pleno de deleite y belleza excepcionales. Un lugar que al inicio del capítulo IV describe en su excepcionalidad inigualable: "Conservo en la memoria el sombreado oasis de árboles inmediato a mi nuevo hogar, en las ilimitadas y herbosas pampas, ante cuyo recuerdo palidece el de cualquier vergel, arboleda o bosque en que yo haya entrado o visto", dice allí (HUDSON, 1958: 67).

Insistamos algo en esta imagen. "[...] [T]odo espaço verdadeiramente habitado traz a essência da noção de casa [...]”, escribe Bachelard en A poética do espaço (BACHELARD, 1978: 200) (cursivas mías). De su afirmación me interesa destacar la expresión "noción de casa", porque pienso que ayuda a comprender el pasaje que acabé de citar, dado que el espacio feliz con el cual el niño evocado pero también el narrador actual postulan una relación de nostalgia, y al que este último reconstruye como una suerte de ámbito sagrado, es aquello que bordea la casa propiamente dicha. Es la pampa en la que está erigida la casa pero también lo que la rodea por todas partes el sitio que en Allá lejos y hace tiempo Hudson evoca como primer universo, como lugar de la ensońación, como el espacio que conserva "centros de tedio, centros de soledad, centros de sueńo". Quiero decir, que es la pampa el sitio evocado como casa porque, tal como sencillamente afirma Martínez Estrada: "La casa donde vive, la casa de la vigilia está afuera" (MARTÍNEZ ESTRADA, 2001: 22). Un espacio del que se puede predicar aquello que Bachelard dice de la casa natal, en tanto está inscripta físicamente en nosotros porque es un grupo de hábitos orgánicos, ${ }^{17}$ hábitos del aire libre en este caso, que el escritor traslada consigo cuando se muda a Inglaterra.

En Allá lejos y hace tiempo no son los cajones, los cofres, los armarios, los sótanos o los desvanes los recintos que guardan los secretos de la memoria sino los alrededores de la casa en los que el niño se aislaba para reflexio-

\footnotetext{
${ }^{17}$ Cito textualmente a Bachelard: "Mas além das lembranças, a casa natal está fisicamente inscrita em nós. Ela é um grupo de hábitos orgânicos” (BACHELARD, 1978: 206).
} 
nar y observar a los pájaros. ${ }^{18}$ Una pampa que la memoria reconstruye con los detalles y la prolijidad de una miniatura, en los que registra los matices del color de los pequeños huevos de los pájaros o el azul purpúreo de las violetas tempranas, como joyas delicadas y mínimas.

Posiblemente es el tratamiento como miniatura de espacio pampeano que, desde la aparición del Facundo, a mediados del silgo XIX, quedó fijado en la literatura y el imaginario argentinos como un lugar sin bordes, aquello que contribuye al encanto que las memorias de Hudson conservan para el lector contemporáneo. Hacer de las grandes extensiones de la pampa una miniatura exige, por un lado, cambiar la disposición de la mirada, aguzarla, demorarse en lo pequeño; es decir, obliga al lector a mirar como mira un niño. ${ }^{19}$ $Y$ pienso que es en ese cambio de perspectiva frente a una imagen fosilizada de la pampa, el lugar en el que Hudson recupera la infancia. Es decir, no en la imagen que cuenta se le entrega como una visión sino en el dispositivo, en la perspectiva que elige para narrarla.

Pero si como creo el ángulo elegido para narrar la infancia es la de la mirada del niño, páginas atrás señalé que en sus memorias conviven dos voces, la voz encantada de los relatos infantiles, que tiene fe en la memoria, y la voz del adulto que ordena el material y que lamenta la pérdida del pasado. Esa voz quejosa se reitera innumerables veces, fundamentalmente en lo que concierne al lamento por la desaparición de los pájaros a manos de los inmigrantes italianos. Quiero, entonces, para concluir detenerme en uno de esos pasajes, porque pienso que concentra el tono y la perspectiva de varios otros esparcidos por el texto. Al promediar el capítulo XX, uno de los últimos, Hudson escribe:

"Tan encantadora parte del bañado, con su bosque de primorosos árboles en miniatura, donde los sociables varilleros cantaban y tejían sus nidos y criaban sus pichones en sociedad, será ahora -atrévome a afirmarlo- un inmenso campo de maíz, alfalfa o lino. Los que hoy trabajan y viven allí, no sabrán nada de

\footnotetext{
${ }^{18}$ Hacia el final del capítulo XX, en que describe un juego con algunos nińos criollos, comenta: "Apenas se terminaba, volvía con una especie de sensación de alivio a mis paseos solitarios y a la observación de la naturaleza [...] (HUDSON, 1958: 3003).

En un sentido similar, en el capítulo XXV, escribe: "Aquello fue cuando los años tenebrosos habían pasado, cuando yo ya gozaba de largos períodos de salud más o menos buena y había conocido la felicidad en los solitarios lugares que me gustaba frecuentar en comunión con la naturaleza y con los pájaros silvestres por compañía (HUDSON, 1958: 349).

${ }^{19}$ Creo que además de esa cierta reducción que sufre la representación del espacio pampeano para hacerlo legible desde la mirada del niño, es posible concebir la construcción de la miniatura en este texto desde la concepción que Susan Stewart le atribuye en El ansia, donde la considera como "una metáfora del espacio interior y del tiempo del sujeto burgués" (STEWART, 2013: 12). Mientras a la pampa sarmienta, en su calidad de espacio sin bordes, podría pensársela en los términos en que la crítica concibe al gigantismo "como una metáfora de la autoridad abstracta del estado y de la vida colectiva” (STEWART, 2013: 12).
} 
los hermosos huéspedes anteriores, ni habrán visto jamás, ni oído hablar, del pecho colorado con su plumaje purpúreo, su copete castańo y su delicado y trémulo canto. Cuando evoco las simpáticas escenas del pasado, y rememoro esos campos de juncos y de flores con sus variadas y diversas especies de pájaros silvestres -la nube de relucientes alas, los gritos que regocijaban el corazón, el goce que todo eso representó para mí en la mocedad-, alégrome al pensar que nunca más los volveré a ver, y que terminaré mi vida a miles de millas de distancia, manteniendo hasta el último momento en mi espíritu la imagen de una belleza que ha desaparecido de la tierra” (HUDSON, 1958: 299).

Se trata de un fragmento que condensa algunas de las líneas de fuerza que articulan Allá lejos y hace tiempo y que, entiendo, son las que impulsan la escritura. Por un lado, Hudson se despide melancólicamente de la belleza que conoció durante la infancia y declara su alegría por no tener que enfrentarse a la pérdida de esos encantos y así poder conservarlos intactos en la memoria. Por otro, la imagen primorosa del pasado, el privilegio de haber disfrutado de esa belleza, se contrapone a la falta de suerte de los trabajadores actuales a quienes les toca conformarse con campos sembrados de alfalfa, lino o maíz; esos trabajadores que por no haber llegado a tiempo no pudieron disfrutar de esa belleza sin igual sobre la tierra.

El pasaje cruza el registro de la fábula o del cuento de hadas, que evoca una imagen armónica de la naturaleza, y lo hace valiéndose de las expresiones características de este tipo de relatos, que remiten a la eternidad del nunca más y el para siempre, con el lamento por la situación a la que el tiempo de la política ha conducido a ese espacio que en el pasado fue sólo de encantos.

Un fragmento en el que se intersectan el deleite sentido en la infancia con la amargura de la adultez y cuya escritura responde al impulso que, según Susan Stewart, rige el proceso narrativo de construcción de la nostalgia. Un proceso mediante el cual "se niega el presente y el pasado recoge la autenticidad de ser, una autenticidad que irónicamente, puede adquirir sólo a través de la narrativa”. Nostalgia, ésta, que "[...] está enamorada de la distancia, no del referente en sí mismo", porque, "no puede sostenerse sin la pérdida" (STEWART, 2013: 47).

Si acordamos con Stewart, la decisión de Hudson de abandonar Argentina e irse a Inglaterra para no volver, no está vinculada a los cambios políticos introducidos en el país a partir del gobierno de Sarmiento, los cuales acaban con el modo de vida que había conocido en su infancia, ${ }^{20}$ sino con una estrategia para poder conservar y añorar la infancia, en la medida que esos cam-

\footnotetext{
${ }^{20}$ En este sentido, Martínez Estrada habla de sus "sus prejuicios de tribu contra la 'civilización' sarmientina que desde la ciudad invadía el campo" y Jean vincula el viaje a Inglaterra como necesario para la construcción de un público lector.
} 
bios lo alejan cada vez más de aquello que en su memoria, entre el recuerdo y la imaginación, vivió entre los cinco y los quince años.

Podríamos asegurar, por lo tanto, que cada vez, y son muchas, que Hudson lamenta la conversión del campo argentino, lo que está llorando es la pérdida de la infancia, pero también podríamos pensarlo desde otro lugar; preguntarnos si la queja insistente de este memorialista, enamorado de la distancia, que cultiva la nostalgia en la decisión de no volver nunca más y mantener ese espacio como pérdida, no habla también de la pertenencia de Hudson a su tiempo, en el sentido en que lo postula Giorgio Agamben, cuando señala que: "Pertenece verdaderamente a su tiempo, es realmente contemporáneo aquél que no coincide perfectamente con él ni se adapta a sus pretensiones, y es por ello, en este sentido, no actual; pero, justamente por ello, justamente a través de esta diferencia y de este anacronismo, él es capaz más que los demás de percibir y entender su tiempo" (AGAMBEN, 2010).

\section{Referencias}

AGAMBEN, Giorgio. Infancia e historia. Buenos Aires: Adriana Hidalgo Editora, 2003. . O que é o contemporáneo? e outros ensaios. Chapecó: Argos, 2010.

BACHELARD, Gaston. "A poética do espaço". In: BACHELARD, Gaston. Os pensadores. São Paulo: Abril Cultural, 1978: 200.

CALVEYrA, Arnaldo. Allá en lo verde Hudson. Buenos Aires: Adriana Hidalgo Editora, 2012.

CALVINO, Italo. "Levedad". In: CALVINO, Italo. Seis propuestas para el próximo milenio. Madrid: Siruela, 1989.

CARRERA, Arturo. "1948: Hudson, un recuerdo feliz". In: CARRERA, Arturo. Ensayos murmurados. Buenos Aires: Mansalva, 2009.

CHEJFEC, Sergio. "Lengua simple: nombre". En: CHEJFEC, Sergio. El punto vacilante. Buenos Aires: Norma, 2005.

DERRIDA, Jacques. Dar (el) tiempo. La moneda falsa. Barcelona: Paidós: 1995.

FRANCO, Jean. "El exiliado nato". In: HUDSON, William Henry. La tierra purpúrea. Allá lejos y hace tiempo. Caracas: Ayacucho, s/f, IX-XV.

HALPERIN DONGHI, Tulio. "Prólogo". En: SARMIENTO, Domingo F. Campaña en el ejército grande aliado de Sud América. México: Fondo de Cultura Económica, 1988.

HUDSON, Guillermo Enrique. Allá lejos y hace tiempo. "Far Away and Long Ago". Trad. Fernando Pozzo y Cecilia Rodríguez de Pozzo. Buenos Aires: Peuser, 1958.

LANGE, Nora. Cuadernos de infancia. Buenos Aires: Losada, 1957.

MARTÍNEZ ESTRADA, Ezequiel. El mundo maravilloso de Guillermo Enrique Hudson. Rosario: Beatriz Viterbo Editora, 2001. 
MERCADO, Tununa. "Testemunho. Verdade e Literatura”. In: GALLE, H.; OLMOS, A.C.; KANZEPOLSKY, A.; ZUNTINI IZARRA, L. Em primeira pessoa. Abordagens de uma teoria da autobiografia. Sáo Paulo: Annablume, 2009: 31-36.

MOLLOY, Sylvia. Acto de presencia. La escritura autobiográfica en Hispanoamérica. México: Fondo de Cultura Econcómica, 1996.

MOLLOY, Sylvia. "Prólogo”. In: LANGE, Norah. Obras completas. Tomo I. Rosario: Beatriz Viterbo Editora, 2005.

MONTELEONE, Jorge. "El deseo de narrar”. In: BENJAMIN, Walter. Historias desde la soledad y otras narraciones. Buenos Aires: El cuenco de plata, 2013.

OCAMPO, Victoria. Autobiografía I. El archipiélago. Buenos Aires: Ediciones Revista Sur, 1982.

OZ, Amós. E a história começa. Dez brilhantes inícios de clássicos da literatura universal. Rio de Janeiro: Ediouro, 2007.

PREMAT, Julio. "Pasados, presentes, futuros de la infancia". Cuadernos LIRICO. Revista de la red interuniversitaria de estudios sobre las literaturas rioplatenses contemporáneas en Francia. 11/ 2014. Disponible en: <http://lirico.revues. org/1736>.

ROSMAN, Silvia. "Entre el deseo y la memoria: relatos de viaje en el Río de la Plata". The Colorado Review of Hispanic Studies, v. 3, otońo, 2005: 131-140.

SARMIENTO, Domingo F. Recuerdos de provincia. España: Salvat, 1970.

STEWART, Susan. El ansia. Narrativas de la miniatura, lo gigantesco, el souvenir y la colección. Rosario: Beatriz Viterbo Editora, 2013.

TERÁN Oscar. "Lección 3. La Generación del 37: Sarmiento y Alberdi”. In: TERÁN, O. Historia de las ideas en la Argentina. Diez lecciones, 1810-1980. Buenos Aires: Siglo XXI, 2008.

WOOLF, Virginia. Momentos de vida. Barcelona: Lumen, 1982.

Adriana Kanzepolsky é Doutora em Língua Espanhola e Literaturas Espanhola e Hispano-americana, pela Universidade de São Paulo e Professora de Literatura Hispano-americana da USP. Entre as publicaçóes recentes figuram "Reverberaçóes do luto ou acerca da morte em família", "La memória justa y las promesas incumplidas: el desperdicio de Matilde Sánchez" e "La que oyó su nacimiento. El eco de mi madre de Tamara Kamenszain”. 